\title{
CORRESPONDENCE
}

The Editor,

\author{
7 Craigmillar Park, \\ Edinburah, 9, 20th November 1952
}

T.F.A.

Dear Sir,

\section{Theory of probabilities}

Some little time ago I wrote a short essay on the subject of probability, which was published in Vol. 19 of the Transactions. This letter is by way of addendum and I should be grateful if you could see your way to publish it.

I left, I think, the conclusion of the essay rather in the air; one quotation will make my meaning clear-" Those who assert the existence of an objective probability ..., must realize that the only conceivable background for this is the positive assertion of individual randomness giving rise to over-riding inflexible law." In any statistical work one undertakes, however, it is from the results of the observed law that one draws one's data and one does not (and cannot) bring into the calculation the underlying idea that all experience consists of a series of amazingly fortunate accidents and that tomorrow there may be a new world. Everything is done upon the basis of observed data and in the confident expectation of regularity-in fact upon a practical assumption of determinism and not upon any theory of probability.

In any case, for me the assertion of a fundamental and absolute randomness is staggering ; the statement, that a thing or a law, of the nature of which one has, ex hypothesi, no knowledge, does not exist, seems to be the quintessence of arrogance. The human mind is an inconvenient partner in all investigations and even if (however impossible it may appear to the layman like myself) it could be shown that no law exists of which the mind can conceive, why should there not be one which lies outside the realm of our under- 
standing? There is no ground for the proposition that our minds are so constructed as to be capable of comprehending the workings of nature ; in fact, there is ample superficial justification for entertaining the contrary view.

It appears to me that there is no logical ground for a theory of probability in practical affairs and that if it must exist, it can only be in the rarified atmosphere of the mathematician's study.

Yours faithfully,

ANDREw R. Davidson. 